\title{
SOCIAL RANK, OBSERVABILITY, AND SEXUAL BEHAVIOUR OF RHESUS MONKEYS (MACACA MULATTA)
}

\author{
L. C. DRICKAMER* \\ Research Division, North Carolina Department of Mental Health, \\ Raleigh, North Carolina 27611, U.S.A.
}

(Received 3rd September 1973)

\begin{abstract}
Summary. The observation that high-ranking male rhesus monkeys (Macaca mulatta) mate more frequently than low-ranking monkeys in a social group is based on the assumption that all males are equally visible to the human observer. The frequency of mating activity in freeranging social bands of rhesus monkeys in the La Parguera, Puerto Rico colony, when corrected for the observability of males, revealed no significant differences in the performance of sexual behaviour by males of differing social ranks. These results fail to support the conclusion that high-ranking male monkeys engage in a disproportionately higher number of sexual acts in a social group.
\end{abstract}

For both wild Indian rhesus macaques (Macaca mulatta) and for populations of this species confined to island colonies off the coast of Puerto Rico, it has been reported that adult males of higher social status mate more frequently with the oestrous females in the social band and thus contribute more to the gene pool of future generations (Carpenter, 1942; Conaway \& Koford, 1965; Kaufman, 1965; Sade, 1968; Lindburg, 1967). Loy (1971) reported that for one social band studied at Cayo Santiago, Puerto Rico, there was no significant pattern, but only a trend for higher-ranking males to engage in more sexual behaviour with the oestrous females. An assumption common to these studies is that adult male monkeys are equally visible to the observer, regardless of their social rank. Since low-ranking and solitary males are more secretive, furtive or peripheral than dominant and high-ranking males, they would be less visible to the human observer and thus their sexual behaviour scores would be underrepresented.

To examine the relationship between social rank and observability of sexual behaviour, I spent $193 \mathrm{hr}$ observing free-ranging Macaca mulatta at La Parguera, Puerto Rico. The La Parguera monkey colony was founded in 1962 (see Vandenbergh, 1967, for detailed description) and at the time of the present study there were four social bands on La Cueva Island ranging in size from 35 to 110 members. Each social band was observed for fifteen to twenty

\footnotetext{
* Present address: Biology Department, Williams College, Williamstown, Massachusetts 01267, U.S.A.
} 
separate sessions totalling 10 to $14 \mathrm{hr}$ per month during the mating season. The mating period lasts from mid-October until late February at La Parguera (Vandenbergh \& Vessey, 1969). No instances of sexual behaviour as defined below were recorded during any month of the year outside the mating season.

During each observation session, which lasted for 30 to $90 \mathrm{~min}$, the frequency of, and participants in, each of the following types of sexual behaviour was noted:

Consort: a paired male-female relationship involving reciprocal grooming and following.

Mating: a sequence of two or more mounts of the female by the male, involving intromission and pelvic thrusts by the male.

Copulation: a terminal sexual mount during which the male showed the ejaculatory reflex, held the final mount for variable periods of time and deposited an ejaculatory plug in the vagina of the female. The final copulatory mount often involved the female hand clasp (Zumpe \& Michael, 1968) and vocalizations by male, female, or both.

Each monkey in the colony had a number tattooed in black ink on the face, chest and inner thigh permitting individual identification. At 5-min intervals throughout each observation, a list was compiled of all adult males and adult females in the band under observation that were in view during the 5-min interval. Social ranks of the adult males were determined from observational data on aggressive encounters made concurrently with the recordings of sexual behaviour. Similar observations of aggressive encounters, both before and after the mating season demonstrated substantially the same social hierarchies among the males of each group.

For analysis, the males within each social band were divided evenly into groups of high, middle or low rank. Mean frequency scores were then computed for all males of high rank, all males of middle rank and all males of low rank and analyses of variance were used to determine whether there were any significant differences among the rank groups. In the second part of the analysis, to answer the original question concerning the assumption of equal observability of all males, a percentage appearance ratio was calculated for each individual male by dividing the total number of 5-min intervals during which that particular male was seen by the total number of 5 -min periods during which I had observed his group. The behavioural scores were then divided by the appearance ratio for each individual male and analyses of variance were used to determine whether there were any significant patterns with respect to rank and sexual behaviour. Males were maintained in exactly the same rank group for the second portion of the analysis as in the tests used on the raw data.

The results (Table 1) show that for the raw behavioural data (first three lines of Table 1), there were significantly more sexual behaviour acts performed by males of high rank. Middle-ranking males exhibited intermediate levels of performance and low-ranking males exhibited the lowest sexual behaviour scores. The same pattern was found for all three behavioural measures.

Analysis of the percentage appearance ratios indicated that high-ranking 
male monkeys were seen significantly more frequently. Middle- and lowranking males were seen considerably less often, scoring only $56 \%$ and $36 \%$ respectively.

The last three lines of Table 1 show the mean behavioural scores after adjustments for each male using the appearance ratios. For each of the three behavioural measures, there were no significant differences across the three rank groups. Trends were evident from the data indicating more sexual behaviour on the part of high-ranking males. Similar trends were reported by Loy (1971) for a social band of rhesus macaques at Cayo, Santiago. Because of wide-ranging variation in the behaviour of individual males in all social rank groups in the present study, the mean values for sexual behaviour were not significantly different across rank groups.

Table 1. Types of sexual behaviour of high-, middle- and low-ranking adult male Macaca mulatta

\begin{tabular}{|c|c|c|c|c|c|}
\hline \multirow{2}{*}{ Condition } & \multicolumn{3}{|c|}{ Rank of male } & \multirow{2}{*}{$\begin{array}{c}F \text {-ratio } \\
(\text { d.f. }=2 \cdot 25)\end{array}$} & \multirow{2}{*}{$\mathbf{P}$} \\
\hline & High & Medium & Low & & \\
\hline $\begin{array}{l}\text { Gonsorts } \\
\text { Matings } \\
\text { Gopulations } \\
\text { Appearance ratio* }\end{array}$ & $\begin{array}{ll}9 \cdot 1 & (1.5) \\
3.0 & (0.7) \\
0.8 & (0.3)\end{array}$ & $\begin{array}{ll}4 \cdot 0 & (0 \cdot 7) \\
1.4 & (0.5) \\
0.5 & (0 \cdot 3)\end{array}$ & $\begin{array}{ll}2.3 & (0.5) \\
0.4 & (0.2) \\
0.1 & (0.1)\end{array}$ & $\begin{array}{r}12 \cdot 90 \\
8 \cdot 19 \\
3 \cdot 54\end{array}$ & $\begin{array}{l}<0.01 \\
<0.01 \\
<0.05\end{array}$ \\
\hline $\begin{array}{l}(\times 100=\%) \\
\text { Consorts/appearance } \\
\text { Matings/appearance } \\
\text { Copulations/appearance }\end{array}$ & $\begin{array}{c}0.82(0.02) \\
11 \cdot 1(1.8) \\
3.6(0.8) \\
1.0(0.4)\end{array}$ & $\begin{array}{l}0.56(0 \cdot 04) \\
6 \cdot 9(0 \cdot 6) \\
2 \cdot 4(0 \cdot 7) \\
0 \cdot 8(0 \cdot 3)\end{array}$ & $\begin{array}{l}0.36(0.05) \\
7.4(1.4) \\
1 \cdot 6(0.7) \\
0.3(0.3)\end{array}$ & $\begin{array}{l}4 \cdot 50 \\
2 \cdot 79 \\
2 \cdot 08 \\
1 \cdot 30\end{array}$ & $\begin{array}{l}<0.025 \\
>0.05 \\
>0.20 \\
>0.20\end{array}$ \\
\hline
\end{tabular}

Mean behavioural scores ( \pm 1 S.E.) are given in the top three lines. Data corrected for the appearance ratios are given in the last three lines (Mean value \pm 1 S.E.). F-ratios and the associated probabilities from one-way analyses of variance are given for each measure.

* For calculation of the appearance ratio, see text.

For each group, the 'alpha male' was either the first or second most visible male in the troop. The degree to which the four alpha males of the four social bands engaged in sexual activity demonstrates the wide variability seen for males of all ranks. In only one troop did the dominant male have the most consorts and perform the highest number of matings and copulations. In another group, the beta male was the most sexually active male. In two of the troops, the third-ranking male engaged in more sexual activity than either the alpha or beta male.

From these analyses, I conclude that the amount of sexual behaviour in which males of different social ranks engage may be related to, but is not a direct function of, social rank. If, in the present study, only the raw data scores had been examined, I would have concluded that high-ranking males perform significantly more matings and copulations in agreement with the studies mentioned previously. By scoring the frequency of appearance of each male, however, it was possible to test the assumption that all males are equally observable. In fact, all males are not equally visible to the human observer. High-ranking males tend to be more conspicuous, at the centre of activity and are much more visible than the furtive, peripheral low-ranking males. 
A parallel assumption concerning the observability of females must also be examined. If most of the females in a social group were present in the observation area most of the time then little sexual behaviour would be taking place out of the area visible to the observer. In the present study, the 5-min interval records were used to determine that only $28 \%$ of the adult females of each troop were visible during any average 5-min interval. The females known to be in oestrus were present in the observation area for only $37 \%$ of the total number of 5-min intervals during which oestrous females were observed. Thus, there could have been many sexual relationships taking place outside the observer's view, involving middle- and low-ranking males and the many females not present in the observation area.

In any study in which conclusions are based on relationships involving social ranks or status in a dominance hierarchy, the relative observability of the animals at various rank levels should be determined. Where observability is the same for all ranks, conclusions may be based directly on the raw data, but in a case such as the one presented here, where the observability is related to social rank, a correction must be applied to the data before conducting any analyses.

The author was supported by NIMH Grant No. MH 19837-01 to Dr John Vandenbergh, Research Division, North Carolina Department of Mental Health, Raleigh, North Carolina, U.S.A. The La Parguera primate facility is operated by the University of Puerto Rico on NINDS Contract No. 71-2003 with the Caribbean Primate Research Center. I thank Dr John Vandenbergh and Dr Clinton Conaway for reading the manuscript.

\section{REFERENGES}

CARPENTER, C. R. (1942) Sexual behavior of free ranging rhesus monkeys (Macaca mulatta). II. Periodicity of estrus, homosexual, autoerotic and non-conformist behavior. J. comp. Psychol. 33, 143.

Conaway, G. H. \& Koford, G. B. (1965) Estrous cycles and mating behavior in a free-ranging band of rhesus monkeys. F. Mammal. 45, 577.

KaUfMan, J. H. (1965) A three-year study of mating behavior in a free-ranging band of rhesus monkeys. Ecology, 46, 500 .

LindBurG, D. (1967) A field study of the reproductive behavior of the rhesus monkey (Macaca mulatta). Ph.D. thesis, University of California, Berkeley, U.S.A.

Loy, J. (1971) Estrous behavior of free-ranging rhesus monkeys (Macaca mulatta). Primates, 12, 1.

SADE, D. S. (1968) Inhibition of son-mother mating among free-ranging monkeys. Sci. Psychoanal. 12, 18.

VANDENBERGH, J. G. (1967) The development of social structure in free-ranging rhesus monkeys. Behaviour, 29, 179.

VANDENBergh, J. G. \& Vessey, S. H. (1969) Seasonal breeding of free-ranging rhesus monkeys and related ecological factors. $\mathcal{F}$. Reprod. Fert. 15, 71.

Zumpe, D. \& Michael, R. P. (1968) The clutching reaction and orgasm in the female rhesus monkey (Macaca mulatta). J. Endocr. 40, 117. 